\title{
Notas Sobre a Educação no Governo Pedro Gondim e a Criação da Escola Normal Estadual de Campina Grande (1955-1960)
}

Records of Education During Pedro Gondim's Government and the Foundation of Escola Normal Estadual in Campina Grande (1955-1960)

\author{
Pâmella Tamires Avelino de Sousa \\ Programa de Pós-Graduação em Educação-PPGE, Centro de Educação-CE, \\ Universidade Federal da Paraíba-UFPB, João Pessoa-PB, Brasil, \\ pamellatasousa@gmail.com. \\ Niédja Maria Ferreira de Lima \\ Programa de Pós Graduação em Educação-PPGEd, Unidade Acadêmica de \\ Educação-UAEd, Universidade Federal de Campina Grande-UFCG, Campina \\ Grande-PB, Brasil, niedjafl@yahoo.com.br \\ Fabiana Sena da Silva \\ Programa de Pós-Graduação em Educação-PPGE, Centro de Educação-CE, \\ Universidade Federal da Paraíba-ÜFB, João Pessoa-PB, Brasil, \\ fabianasena@yahoo.com.br
}

\begin{abstract}
This study presents the State Normal School of Campina Grande (1960), the first public institution in the city for teacher training. We considered the relevance of the study in the theme of school institutions, conceiving the school as a product of society (Tanuri, 2000, Nosella And Buffa, 2013; Saviani, 2007), resorting to documentary sources, periodicals from the 1950s and 1960s. From the analysis, we were able to know the public educational prerogatives for this municipality, identifying the main subjects involved in the creation of the school. We highlight as relevant the developmentalist nationalist period in the speeches of local leaders and as results the temporal mismatch of the creation of the school, as well as the involvement of Governor Pedro Moreno Gondim in providing the city with a Normal School for girls. Keywords: Normal School. Campina Grande/PB. Pedro Gondim.
\end{abstract}

\section{Resumo}

Este estudo apresenta a Escola Normal Estadual de Campina Grande (1960), primeira instituição pública da cidade para formação de professoras. Consideramos a relevância do estudo na temática de instituições escolares, concebendo a escola enquanto produto da sociedade (Tanuri, 2000, Nosella E Buffa, 2013; Saviani, 2007), 
recorremos às fontes documentais, periódicos das décadas de 1950 e 1960. A partir da análise, pudemos conhecer as prerrogativas educacionais pública para esse município, identificamos os principais sujeitos envolvidos na criação da escola. Destacamos como relevante o período nacionalista desenvolvimentista nos discursos dos dirigentes locais e como resultados o descompasso temporal da criação da escola, bem como o envolvimento do governador Pedro Moreno Gondim em proporcionar para cidade uma Escola Normal para moças.

Palavras-chave: Escola Normal. Campina Grande/PB. Pedro Gondim.

\section{Introdução}

No que concerne a efetiva criação da Escola Normal Estadual de Campina Grande-PB, evidenciamos um descompasso em relação a outras instituições e especialmente em relação à primeira instituição pública para formação de professores no estado paraibano: a Escola Normal da Parahyba que foi instaurada a partir da lei 761 e "[...] promulgada em 7 de dezembro de 1883 e regulamentada em 30 de junho de 1884, [que] havia extinguido o Liceu Paraibano, implantando uma Escola Normal de dois graus" (Kulesza, 2008, p. 263). Já a primeira instituição pública para formação de professores no município campinense somente vem a ocorrer no final do ano de 1959 e deliberadamente em 1960.

A cidade de Campina Grande, por se tratar de um local de efervescência política e desenvolvimentista, apresentou desde sua emancipação em 1864 um forte crescimento econômico, chegando à década de 1950 a arrecadar "[...] Cerca de quarenta por cento da arrecadação estadual de tributos" (Agra Do Ó, 2006, p. 30). Diante desse argumento, indagamos qual o papel educacional desenvolvido nessa sociedade e quais as prerrogativas anunciaram a criação de uma instituição formativa docente tardiamente?

Esse estudo apresenta resultados coletados mediante a consulta de documentos, tais como jornais e revistas que circularam no âmbito estadual e municipal no período estudado, como documentos legais que corroboraram para criação da instituição. Destacamos o posicionamento do primeiro governo de Pedro Moreno Gondim (1958-1960) por esse ser referido nos documentos como uma das peças chave para criação da Escola Normal Estadual de Campina Grande, bem como o aspecto social que suscitou a origem dessa escola, destacando o contexto social e as ações políticas envolvidas nesse processo. Para a localização de documentos e outras fontes, realizamos a consulta nos arquivos João Agripino, pertencente à instituição em estudo, compreendendo os dados históricos da Escolai (Fichas de matrículas das alunas pioneiras e Histórico Escolar), bem como o acervo da Biblioteca de obras raras Átila Almeida, pertencente à Universidade Estadual da Paraíbaii. Essa instituição possui um acervo favorável de periódicos da cidade no período estudado, a exemplo do Diário da Borboremaiii "Desde que começou a circular, o jornal foi testemunha dos principais fatos que hoje compõem a história de Campina Grande e acompanhou os principais desdobramentos da política e daqueles que ajudaram a cidade a se desenvolver" (Fernandes, 2011, p. 1), cabe mencionar o Arquivo Histórico Waldemar Bispo Duarte, pertencente à Fundação Espaço Cultural da Paraíba (FUNESC), que dispõe de jornais, fotos e documentos oficiais de todo o Estado. Dessa forma, Tanuri (2000), Nosella e Buffa (2013), Vicentini e Lugli (2009), Saviani (2007), entre outros autores embasaram esta 
pesquisa, situando a sua relevância na temática de instituições escolares, bem como a constituição de escolas enquanto algo intrínseco a sociedade.

Consideramos o posicionamento que a história não será contada da real forma como aconteceu, porém o uso de documentos como fontes investigativas nos aproximaram desse momento vivido. Nosso intuito não é explicar a realidade ou simplesmente compreendê-la, pois a atividade cientifica da qual desenvolve 0 pesquisador está arraigada ao movimento de transformação e construção de bases teóricas (Wachowicz, 2001).

\title{
A Educação no Governo de Pedro Gondim (1958-1960)
}

\begin{abstract}
O Governador do Estado prometeu que funcionaria, a partir deste ano o Curso Normal Estadual. Começaria por funcionar anexo ao Colégio Estadual. Um curso preparatório foi instalado. Mas o Curso Normal não vem. Por que? Agora estão dizendo que os deputados adversários do Governador estão dispostos a não aprovar a mensagem que cria o Curso Normal de Campina Grande, para não dar oportunidade de melhorar a média de simpatia dos campinenses para o sr. Pedro Gondim. Que tem com isso os estudantes? Será que para certo os deputados política é interesse deles e de seus grupos partidários e não abre posição de favorecer um bem comum? (Gazeta Campinense, 1960, p. 3).
\end{abstract}

O trecho apresentado, retirado de uma fonte primária, revela algumas nuances acerca do processo de criação e funcionamento da Escola Normal Estadual de Campina Grande. O periódico campinense: Semanário Gazeta Campinense; circulou na sociedade no início da década de $1960^{\mathrm{iv}}$ e publicava notícias acerca do cenário político e educacional da cidade. Nesta seção, em específico do jornal, são questionados os debates acerca dos problemas educacionais por parte dos estudantes, que comentam suas atividades e possíveis descasos. No entanto, é dedicado outro espaço no periódico do qual se recomenda atenção aos escritores, por se tratar de um espaço de socialização onde seriam destacados apenas atitudes que representassem o bem comum.

$\mathrm{Na}$ referida citação do periódico, constatamos a atitude de instauração do Curso Normal em Campina Grande, como uma das políticas do governo de Pedro Gondim, apesar de promessa, conforme os alunos apontam a atuação não era bem como planejado. A notícia exibida apresenta alguns elementos de outra fonte consultada no Memorial da Assembleia Legislativa paraibana: o anteprojeto encaminhado em outubro de 1959, no qual o governador Pedro Gondim, afirma que a criação da escola para Campina Grande é uma das "[...] diretrizes da política educacional do seu Governo, empenhado na expansão do ensino normal com o intuito de no Estado aumentar o número de professoras diplomadas" (Paraíba, 1959). Ademais, cabe destacar que o incentivo à criação de cursos de aperfeiçoamento docente correspondia a uma prática de cunho nacional. A renovação das práticas educacionais culminou em projetos e campanhas desenvolvidos pelo Inep e MEC. Cabe mencionar que a década de 1950 foi composta por um cenário de impulso ao desenvolvimento. Novas relações sociais se impunham entre elas a industrialização que requeria força de trabalho especializado, que, consequentemente, foi impulsionada a renovação no curso de formação de professores, por meio de especializações e criação de novas instituições destinadas ao preparo docente..

Entendidas como estratégias de intervenção do órgão responsável pela organização do ensino em nível nacional, tais campanhas expressam as 
preocupações dos educadores nucleados no MEC em adequar o sistema de ensino às expectativas de profissionalização do magistério e de renovação das práticas pedagógicas em curso (XAVIER, 2008, p.129/130).

Em todo o cenário nacional o projeto "desenvolvimentista" teve envolvimento político dos intelectuais, pois entendiam esse momento como propício a renovação. E a educação pública amplia-se enquanto requisito formador para a industrialização brasileira. Em Campina Grande, já desde a década de 1930 com a riqueza do algodão, a cidade vivia auspiciosos ares de modernidade, no entanto contrastava com altos índices de analfabetismo (Rodrigues \& Silva, 2012). Com o declínio da cultura algodoeira é a partir da década de 1960 que os dirigentes campinenses empreendem um novo momento para ressignificação da economia. Mendonça e Xavier (2008), destacam no período de 1955-1965

[...] uma multiplicidade de ações emanadas do Ministério da Educação com o objetivo de enfrentar as demandas da sociedade por ampliação do acesso à educação escolar. Ao mesmo tempo, observamos o empenho das demais instâncias de governo, em nível estadual e municipal, em dar uma resposta às pressões em prol da ampliação e da melhoria da qualidade do ensino. (p. 28).

O objetivo em ampliar a educação trata-se de um contexto mais amplo. Semelhante a esse movimento, o governo paraibano ratifica a instauração e renovação dos cursos para formação de professores. No caso da cidade de Campina Grande, esta por não possuir até a década de 1960 escolas públicas para formação de professoras, passará então a contar com essa modalidade de ensino, ressaltando que o seu funcionamento, conforme oficio encaminhado à Assembleia Legislativa em 26 de outubro de 1959, pelo governador Pedro Gondim, cita:

A exemplo do que já ocorreu nesta Capital ao instituto de Educação, que, por anos ocupou várias salas do Colégio Estadual de João Pessoa, a Escola Normal ora em projeto funcionará no Colégio Estadual daquela cidade, até que venha a construir o seu edifício próprio. (Paraíba, 1959).

Observamos uma concordância no que tange ao estabelecimento no primeiro ano de criação da escola. Porém, não podemos deixar de evidenciar que na citação da matéria do jornal Gazeta Campinense no ano de 1960 a escola é referenciada enquanto um curso preparatório e, em seguida, como uma ação lenta por ocasião da política local. A instalação do curso normal previa uma necessidade da política não apenas local, mas nacional, com ênfase a universalizar a educação, bem como aumentar os níveis de escolarização objetivando sujeitos aptos ao serviço industrial. Para tanto se demandava um maior número de professoras com diplomas. Ainda sobre a leitura do oficio evidenciamos a posição do governo em estabelecer o funcionamento no Colégio Estadual como algo corriqueiro, uma vez que aconteceu de maneira idêntica na capital paraibana.

Nessa perspectiva, a presença da Escola Normal para a cidade demandou mais que o interesse estatal, também impôs ao cenário social da cidade de Campina Grande uma crítica por meio dos jornais, em relação à educação pública no município, sendo considerada como algo esquecida, como também o impulso de valorização e modernidade da cidade, da qual requeria em seu contexto edificações que valorizassem à educação enquanto promotora do desenvolvimento.

Durante a década de 1960 o comércio algodoeiro já não possuía o mesmo impacto das décadas anteriores, ademais o comércio citadino apresentava 
modificações. Esse cenário corroborou para a necessidade de ampliar o processo de industrialização da cidade, principalmente com o advento de ofertas para subvenção de impostos e instalação dessas indústrias (AGRA DO Ó, 2006). De acordo com Costa (2013, p. 50), a necessidade de aumentar a quantidade de indústrias também se dava por "[...] conta da mão de obra crescente de imigrantes que haviam chegado à cidade da zona rural e aos municípios vizinhos e do sertão paraibano, que estavam à margem do processo de urbanização da cidade."

O cenário de crescimento atribuído ao município de Campina Grande se situava em um contexto de constante desenvolvimento, porém estagnado frente às mudanças econômicas. A inserção das indústrias passou a exigir uma mão de obra mais qualificada e o crescimento da cidade aspirava por cidadãos com acesso à escola que tivessem um nível de educação capaz de afeiçoar sentimentos pela nação.

Nessa conjuntura, o modelo nacional desencadeava suas aspirações para o desenvolvimento, de modo que a educação assumia o papel protagonista na ação de auxiliar o auspicioso crescimento da nação. A partir desse contexto compreendemos a difusão dos Cursos Normais como panorama de "Um dos traços dominantes da política educacional do atual Governo tem sido a expansão do ensino normal, com o objetivo de evitar, dentro de poucos anos, que o Estado continue a lançar mão de professores leigos no Ensino Primário" (União, 1959, p. 3).

Outro periódico, o jornal $A$ União, importante circulação no estado paraibano, denotava a ação da preocupação para com a educação como um traço marcante do governo Gondim. Cabe mencionar que é o jornal mais antigo do Estado, por possuir mais de 120 anos, editado na cidade de João Pessoa, e é único jornal oficial ${ }^{\vee}$ estadual ainda existente no Brasil. Compreendemos a leitura do oficio como semelhante com o noticiário do periódico, são documentos oficiais do governo. Assim, afirmar que o ensino normal se apresenta como uma preocupação do governo é lançar mão de que a política estadual precisa reforçar esse discurso.

Em outras matérias do jornal $A$ União, são descritas as ações da Secretaria de Educação e Cultura com as instituições particulares para formação de professores, de modo que se destaca pelo órgão "[...] os melhores esforços no sentido de que os colégios particulares se fundem cursos pedagógicos, ou seja, estes restaurados onde quer que tenham sido ministrados" (União, 1959, p. 3).

[...] vem estimulando os estabelecimentos de estudo particular disseminando-os pelo interior do Estado a que instalem, restaurem ou revigorem os seus cursos normais, o que não se tem traduzido em mera sugestão/ou apelo, mas também por assistência técnica ao professorado, como se fez com o curso de aperfeiçoamento para professores escolas normais particulares. (Paraíba, 1959).

Em ambas as leituras dos documentos, tanto do jornal $A$ União quanto do oficio notamos a presença da iniciativa privada em corroboração com a atuação do Estado, visto que a presença de escolas para formação docente públicas era praticamente inexistente. Dessa forma eram empreendidas reformas e reestruturações nas instituições consideradas como tradicionais, isto é, particulares, como necessidade de favorecer uma educação própria e que solucionasse o problema da universalização do ensino. No caso de Campina Grande, ainda acentuamos o crescimento industrial que exigia um número de pessoas qualificadas para o trabalho e, a cidade contava com outras instituições de ensino particulares, que ofereciam cursos pedagógicos ou estavam equiparadas a Escola Normal de João Pessoa. 
Ao tratar das medidas formativas para a cidade de Campina Grande, ainda no jornal $A$ União, percebemos o destaque para a criação da Escola Normal Estadual, enfatizando que

No próximo ano, funcionará a Escola Normal Estadual de Campina Grande, cujo ante-projeto aguarda discussão na Assembleia Legislativa do Estado. Já se instalaram e entrarão em funcionamento no próximo ano, atendendo os apelos da Secretaria, os Cursos Pedagógicos do Colégio Nossa Senhora de Lourdes e do Colégio Nossa Senhora das Neves, ambos desta cidade. (União, 1959, p. 3).

Esse era um plano educacional para cidade destacado também no Diário da Borborema (Agra Do Ó, 2006). O anseio de crescimento era algo constante e para seu cumprimento existiam metas políticas, os dirigentes deveriam "[...] apenas saber aproveitá-lo, direcioná-lo, providenciando para que determinadas carências fossem supridas e tudo pudesse seguir o seu curso natural' (Agra Do Ó, 2006, p. 36, grifo do autor). Os problemas campinenses foram elencados em uma lista considerada breve, mas urgente frente à solução para o crescimento da cidade "[...] água, pavimentação, Instituto de Educação, Escola Normal para moças, grupos escolares, ampliar e melhorar a saúde, ajuda para a agricultura, hospitais, obras sociais" (Diário Da Borborema, 1959).

O cenário de anseio nacional que se estendia até os governos estaduais e se pulverizava nas cidades interioranas são oportunos para breve compreensão da atuação educacional do governo de Pedro Gondim. Sua atuação aconteceu "[...] entre 1958-1960, quando ele ocupou o cargo substituindo o então Governador Flávio Ribeiro Coutinho, visto que estes primeiros anos no poder do Estado foram fundamentais para traçar seu perfil enquanto homem público" (ARAÚJO, 2009, p.10). A autora destaca que "[...] Gondim assume o poder, sobretudo, no que concerne à política desenvolvimentista e aos planos de 'salvação' para o Nordeste" (2009, p. 27). Essa visão norteia todo o pensamento desenvolvimentista acerca do crescimento campinense que almejava por seus dirigentes posicionamento referenciado frente ao Estado.

\footnotetext{
Pedro Gondim, concomitantemente ao período J.K., ou seja, o período de dois anos no qual ele ficou no poder de forma interina, percebemos que as apresentações que envolviam o governador buscavam constantemente cristalizar no imaginário local, a ideia de que Gondim era o político necessário à Paraíba naquele momento. As representações, assim como os valores simbólicos da sociedade paraibana, eram manipulados pela imprensa estatal para que fosse possível promover uma atmosfera de tranquilidade e desenvolvimento para o Estado, tal como se anunciava no cenário nacional. (Araújo, 2009, p. 27).
}

O governo de Pedro Gondim se deu em um momento propício para o desenvolvimento também de contexto nacional e, embora a região Nordeste enfrentasse diferentes problemas: econômicos; seca e analfabetismo de grande parte da população, a atuação do governador foi acentuada de forma quase predominante como positiva nos jornais do Estado ${ }^{\text {vi }}$ o que identifica uma imagem ativa para o homem político, merecedor de demonstrações de afeição.

As medidas cabíveis e possíveis ao governo, como restabelecimento do abastecimento d'água em algumas cidades do Estado eram tomadas com presteza, e automaticamente transformadas em discursos das 'grandes 
ações de Pedro Gondim em favor do povo da Paraíba'. Essas obras fomentavam o enaltecimento empreendido pelo Jornal à figura pública do governante, e ao mesmo tempo, eram apontadas como portas abertas ao sentimento de gratidão que a população beneficiada nutria sobre o seu governador. (Araújo, 2009, p. 32, grifo do autor).

O governo tinha em seu favor a propaganda lançada em sua figura o que propiciava um reconhecimento favorável ao desenvolvimentismo. Atrelada a essa representação, Gondim também é reconhecido por sua influência frente ao governo federal "[...] a propósito de toda essa representação de ativismo que se construía em torno de sua imagem e de sua administração, não se negava em recorrer ao Governo Federal para ver solucionada as necessidades dos pobres da Paraíba" (Araújo, 2009, p. 31). Toda essa representatividade recebia

[...] o apoio e as homenagens partiam de diferentes locais do Estado, como Areia, Serraria - centro das atividades políticas de Pedro Gondim -, Piripirituba, Cuité, Araruna, Belém e Campina Grande, e eram dirigidas por lideranças, políticos, deputados, prefeitos, e é claro, também pelo povo, representados, sobretudo por organizações de bairro e associações de trabalhadores. (Araújo, 2009, p. 32, grifo do autor).

Em torno dessa figura notória foi construído um símbolo de político popular, uma vez "[...] que através de suas práticas de governo conseguia a cada dia angariar adeptos para junto de si, além de imprimir sua marca de administração dinâmica ao governo do Estado" (ARAúJO, 2009, p.33). Essas ações não se restringiram apenas as obras e soluções para a seca. Em matéria o Semanário Gazeta Campinense destaca que o governador estar

[...] recuperando a administração e prestígio de que gozava nesta cidade e que ficaram patentes pela maneira como nosso povo sufragou o seu nome nas eleições de 3 do outubro do ano passado.

Algumas obras do Estado vão ser iniciadas em Campina Grande notadamente serviços mais amplos de pavimentação das ruas a construção do Parque de Exposições animais a construção do auditório Estadual conforme declarou a reportagem do Diário da Borborema o próprio chefe do executivo estadual.

Serão realizações de grande interesse para a nossa cidade não resta a menor dúvida através dela sou senhor Pedro Gondim tornará a ser o governante amigo dos Campinenses que foi durante a sua intimidade na chefia do governo.

\section{OUTRAS REALIZAÇÕES}

Há, no entanto algumas outras realizações do governo do estado a quais chamamos a atenção do Governador.

Destacamos dois graves problemas o da educação primária e da Saúde Pública.

No setor da educação Campina Grande necessita de mais dois grupos escolares com urgência como meta é imediata os grupos escolares existentes precisam de reaparelhamento, mas a carência escolar nesta cidade reclama e exige sem perda de tempo a instalação de mais unidades de ensino do tipo de grupos escolares bem aparelhados bem dirigidos servido das professoras dedicadas e competentes. (Gazeta Campinense, 1961 , p. 2, grifo do autor). 
A representatividade do governador ficou relacionada a promessas que almejavam o progresso. Dentre as atividades construtivas mencionadas, o jornal enfatiza como grave problema a educação e saúde, no que concerne explicitamente à educação, em particular, ao ensino primário, alvo para visibilidade da formação de novas professoras. Ainda mais adiante, Gazeta Campinense expõe também a necessidade de criação de mais grupos escolares, o que nos faz imaginar o número de alunos a serem atendidos, consequentemente o aumento no quadro docente, em seguida observamos o termo reaparelhamento como uma das necessidades para eficiência do ensino, seguido da boa direção para os grupos e uma equipe de professoras dedicadas e competentes. Cabe mencionar que a educação é concebida enquanto vocação da mulher, de modo que a dedicação sobrepõe a competência (CHAMON, 2005). No que diz respeito ao direcionamento, esta matéria não deixa claro se a atuação seria destinada às mulheres ou aos homens.

Ainda acerca dos periódicos da cidade e do Estado que veiculavam as ações propostas e, por vezes, lembretes das possíveis ações do governo concernente a esse período, corroboramos com o posicionamento de Agra do Ó (2006, p.41) ao afirmar que "[...] A ideia de Estado, como imagina, amplia para as esferas as relações sociais mais amplas a crença na identidade única”. Dessa forma, o povo passa a associar em uma figura política a imagem de uma possível semelhança e condições igualitárias entre as diferentes classes.

\section{Os Planos Educacionais para Campina Grande}

O Ensino Normal foi, como se sabe, uma das chaves da pedagogia anisio teixeiriana. (Soares, 2016, p. 54).

Ao destacamos o Ensino Normal como uma das propostas conhecidas para os projetos educacionais de Anísio Teixeira, corroboramos com Soares (2016) em perceber esse encantamento no pensamento de educadores paraibanos. Nesse sentido, compreende-se a nota circulada no periódico paraibano

\footnotetext{
VINTE MILHÕES DE CRUZEIROS PARA CONSTRUÇÃO DA ESCOLA NORMAL DE CAMPINA GRANDE

Em fevereiro deste ano, viajando ao Rio o Prof. José Pedro Nicodemos, atual titular da Secretaria de Educação e Cultura, levou um memorial ao Professor Anísio Teixeira, diretor do Instituto Nacional de Estudos Pedagógicos (INEP) em que, representando o Governo do Estado, formulava pedido de financiamento para construção da Escola Normal de Campina Grande, cujo anteprojeto de criação já foi enviado à Assembleia Legislativa pelo Governador Pedro Gondim.

Tenho necessidade de entrar novamente em contato com o INEP, para o qual remeteu relatórios dos trabalhos em andamento neste Estado em colaboração com o referido órgão do Ministério de Educação, o Secretário da Educação e Cultura se fez representar pelo professor Milton Paiva, diretor do Departamento de Educação que acaba de endereçar o seguinte despacho telegráfico 'Informo caro amigo direção INEP a quem renovei apelo essa Secretaria formulado inicio corrente ano dedicou empregar vinte milhões de Cra construção Escola Normal de Campina Grande devendo remeter ainda este exercício vinte milhões de Cruzeiros. Início obras. Em contato pessoal manteve Professor Anísio Teixeira em terei aquele llustre Educador esforço vem sendo feito sentido melhorar padrões Ensino Normal para Estado. Aba. MILTON PAIVA'.
} 
Vem assim o INEP conjugar seus esforços com o Estado, cooperando na realização do edifício próprio da Escola Normal de Grande, que funcionará a partir do próximo ano no Colégio Estadual daquela cidade até que seja concluído o seu prédio. (União, 1959, p. 1).

Essa matéria evidencia o que apresentamos anteriormente: o anteprojeto de criação apresentado a Assembleia Legislativa por intenções do governador Pedro Gondim. No entanto, a notícia também nos esclarece detalhes acerca do financiamento e atuação do INEP, com menções a figura de Anísio Teixeira para construção da Escola Normal. Apesar da construção ainda ser algo em planejamento, tanto a nota do jornal quanto o documento do anteprojeto menciona a criação da instituição para o ano de 1960, com funcionamento em tempo provisório no Colégio Estadual da cidade.

Nas entrelinhas dessa nota, percebemos que o projeto de criação da Escola Normal de Campina Grande foi um plano do início do ano de 1959, uma vez que o Prof. José Pedro Nicodemos, conforme mencionado na notícia, viajou para o Rio de Janeiro no mês de fevereiro, onde, em representação do governador, endossou um documento no qual já continha o plano de criação da escola. A representatividade de apresentar o documento ao diretor do INEP corrobora com o papel de destaque de Anísio Teixeira, bem como configura a preocupação do educador frente à formação docente.

A cidade de Campina Grande, até a década de 1960, não possuía uma instituição pública para formação de professores em nível secundário. Conforme Soares (2016), na década de 1950, a cidade contava com uma instituição de $1^{\circ}$ Ciclo o Curso Normal Regional Nossa Senhora do Rosário e as Escolas Normais de $2^{\circ}$ Ciclo Escola Normal Imaculada Conceição; Escola Normal Alfredo Dantas, todas em caráter privado, sendo duas pertencentes à ordem religiosas. Nos registros da Escola Normal Alfredo Dantas, não foram encontradas fontes que esclarecessem o motivo ou necessidade de sua criação. No entanto, Soares (2016) revela que no Regimento Interno da escola constava no Art.2 a presença exclusiva para formação de professoras.

Segundo Andrade e Cury (2013), o funcionamento da Escola Normal nessa instituição advinha de uma contribuição as Escolas Anexas, dentre elas a Escola Normal de João Pessoa. A escola era:

[...] o Instituto Pedagógico, fundado em 17 de fevereiro de 1919, na Rua Barão do Abiaí, Campina Grande - PB, primeiramente com ensino primário e secundário para ambos os sexos, composto de duas cadeiras regidas pelos fundadores do Instituto, a cadeira masculina pelo tenente Alfredo Dantas Correia de Góes e a cadeira feminina pela professora normalista Ester de Azevedo. Em 1924, o Instituto muda-se para um novo prédio, na mesma rua Barão do Abiaí, sendo adaptado para melhores condições higiênicas e pedagógicas, com mobiliário escolar e pedagógico. Ampliou-se os cursos, e funda cursos profissionais também, Normal e técnicocomercial, sendo apenas em 1929, pelo Decreto n.1615, de 09 de Dezembro de 1929, do Governo do Estado, integrou o Instituto pedagógico nas prerrogativas da Escola Normal Oficial do Estado. (Lima, 2013, p. 5).

Por muito tempo esta instituição foi uma das principais instituições para educação feminina no município. Entre as décadas de 1920 e 1930, o Instituto Pedagógico era a referência de ensino modernizante, com regras de higiene e padronização do comportamento dos alunos (ANDRADE e CURY, 2013). Esse cenário corrobora para participação feminina na escola, visto à necessidade de 
impor à cidade as possibilidades de modernização por meio da educação e dos valores femininos.

O período auge desta educação concerne com o momento de crescimento econômico na cidade de Campina Grande. Na década de 1930, a cidade importava algodão, o que the rendeu visibilidade no cenário nacional, uma vez que passou a arrecadar mais impostos que a capital, João Pessoa. Esse desenvolvimento econômico permitiu a Campina Grande um status modernizante frente às outras cidades interioranas. Diante desse auge, a urbanização da cidade acelera em passos largos e algumas debilidades passam a surgir no municípiovii.

No que concerne à Escola Normal Estadual de Campina Grande, o anteprojeto de Lei 543/55 de 12 de janeiro de 1960

Art. $1^{\circ}$ - Fica Criada a Escola Normal Estadual de Campina Grande, destinada à formação de professoras primárias, através do curso pedagógico (ensino normal de $2^{\circ}$ ciclo).

Art. $2^{\circ}$ - A Escola Normal Estadual de Campina Grande ministrará o curso pedagógico em três séries anuais, devendo observar todos os preceitos constantes na legislação do ensino/normal em vigor e seguir a orientação emanada da Divisão do Ensino Normal, do Departamento de Educação. (Paraíba, 1960, p. 1).

Distinguindo-se apenas do Curso Normal Regional Nossa Senhora do Rosário, a Escola Normal Estadual de Campina Grande seguia os mesmos preceitos das duas instituições particulares já mencionadas. $O$ que nos pressupõe observar que ainda na década de 1950 o município apresentava fortes atitudes clientelistas e patriarcais para com a educação. Mais uma vez o documento evidencia o público alvo para quem era destinado à formação docente, as mulheres, e esclarece também o regimento legal a ser seguido, isto é, o Departamento de Educação Divisão do Ensino Normal paraibano que dispunha de leis organizacionais do Ensino Normal.

Em um trecho do Semanário Oficial da Prefeitura Municipal do ano 1955, ao tratar do ensino primário municipal, se condiz às atividades realizadas anteriormente nos grupos escolares como prejudiciais à educação e que estas seriam resolvidas mediante a contratação efetiva de professoras "diplomadas ou não" que "revelarem qualidades e aptidões para o magistério". Esses registros nos chamam atenção, pois em seu contexto define a visão da professora que atua na educação primária e nos remete a necessidade de instrução escolar no âmbito da formação primária e secundária como algo advindo não apenas no ano de criação da Escola Normal Estadual de Campina Grande.

Em outra notícia publicada para o ano seguinte no Semanário Municipal (1956), Maria Dulce Barbosa, Ex - Diretora apresenta um relatório ao prefeito, em que destaca como finalidades da equipe de professoras os seguintes dados:

[...] O município conta com 23 professoras diplomadas. 140 professores concursados ou possuidoras de certificados vários, 80 tem concurso, com nomeação a título precário, por falta de verba para subvenções [...]

[...] Criação do Curso de Férias, que permita ao professorado municipal melhorar seus conhecimentos [...]

[...] Padronização do Professorado Municipal abrangendo, $1^{\circ}$ as tituladas pelo curso normal ou pedagógico; $2^{\circ}$, as que possuam curso ginasial completo, básico ou cursos especializados; $3^{\circ}$, as que apresentarem certificados de cursos ou concursos. 
Lembro ainda a inclusão, no orçamento de 1957, de uma verba que permita subvencionar, as professoras não padronizadas" (Prefeitura Municipal De Campina Grande, 1956, ANO I, n²7).

A Ex-Diretora do ensino expõe em seu relatório a urgência de professoras preparadas, tal assertiva nos é permitida através dos termos precário, melhorar. Ainda nos atemos ao posicionamento de sugestões para melhoria do ensino, tais como padronização, onde se cogita a similitude do professorado, uma vez que existia uma diferença no que concerne ao grau de ensino. Conforme a ex-diretora se fazia necessária uma equiparação da classe docente, bem como cabe mencionar também o problema orçamentário, onde por duas vezes nesse breve trecho do relatório a autora posiciona o termo verba e salienta a necessidade da inclusão no orçamento municipal.

Em outro contexto, distante dos relatórios educacionais a urgência educacional no município se revela, conforme Agra do Ó (2006), mediante a campanha eleitoral de 1959 uma história "[...] um tanto difícil de entender, como se à frente de cada um se pusesse um quebra-cabeça em que as peças não se encaixavam muito adequadamente" (p. 87). Nessa campanha, um Plano de Governo por escrito altera todas as motivações eleitoreiras e abre discussão para muitas questões, entre elas o projeto desenvolvimentista acentuado no programa e a educação "[...] ali percebida como uma das experiências que deviam ser repensadas a fim de que se tornassem caminhos necessários para o desenvolvimento de Campina Grande" (Agra Do Ó, 2006, p. 16).

Acentuamos a educação em Campina Grande como uma concessão, sendo privilégios de poucos. A formação docente para o primário apontava inúmeras críticas, registradas em matérias do Diário da Borborema nos anos de 1958 e 1959. Encontramos no período estudado notícias que referenciavam ser necessário solucionar a decadência do ensino primário. Outras matérias evidenciam a preocupação com ensino e motivam por meio de enquetes as soluções desejadas pela sociedade.

Em relação ao Semanário Municipal, as edições seguintes destacam a participação de professoras primárias em cursos de aperfeiçoamento no INEP. O documento exibe também o empenho do prefeito Elpídio de Almeida frente à necessidade educacional e mediante esse anseio a vitalidade em dispor de bolsas de estudos com cunho formativo para essas docentes que se aperfeiçoariam e trariam para a cidade as inovações educacionais.

O Semanário expõe a notícia "Reestruturação do Ensino Primário Municipal" (Prefeitura Municipal De Campina Grande, 1957, p. 1). No discorrer da matéria apresenta-se o curso de Psicologia Educacional e Orientação Pedagógica a ser realizada pelas professoras. Fica evidente a necessidade de uma nova posição a ser adotada pelas professoras municipais. O governo municipal empenha forças em oferecer cursos de formação para as professoras dos grupos escolares como medidas de solucionar o mencionado fracasso da educação primária campinense (Diário Da Borborema, 1958).

Em uma enquete intitulada "O que o povo deseja" realizada pelo jornal Diário da Borborema, em 3 de janeiro de 1958, é destacado os problemas educacionais "A educação do povo, por, exemplo, também considerada por muitos dos entrevistados da nossa reportagem, está na base da solução, não imediata, porém de longo prazo, de muitas das más direções que temos tomado no processo de evolução do país" (Diário Da Borborema, 1958, n 75, p. 2). O jornal enfatiza que, diante de uma série 
de obras inacabadas, a educação possui papel preponderante para o desenvolvimento.

Aliado a esses discursos, o jornal informava diariamente acerca dos cursos superiores e técnicos que estavam sendo instalados na cidade. Visto de forma muito positiva, essas notícias reforçavam nos jornais o cenário promissor da cidade.

No que concerne ainda ao ensino secundário, esse era tratado como de grande importância a se valer o ensino primário na cidade de Campina Grande com deficiências e dificuldades na organização, administração, avaliação e no exercício do magistério como nos mostra o noticiário de 14 de janeiro de 1958:

[...] O ensino secundário está popularizando-se cada vez mais acentuadamente. Constitui já uma aspiração comum, quase do mesmo porte que, em outros tempos se prestava à necessidade da simples alfabetização.

[...] Mas é justo que o Estado cuide com maior empenho do ensino primário, preparatório para os estágios sucessivos do currículo, aumentando o número de unidade de ensino básico, aparelhando-as devidamente de material didático, provendo-as de professoras competentes e dedicadas, dando-Ihes orientação e fiscalização assíduas e, enfim, remunerando condignamente o professorado, a fim de poder dele exigir o conveniente em matéria de eficiência. (Diário Da Borborema, 1958, n 81, p. 2).

No dia seguinte a esta publicação, a notícia intitulada "Pela melhoria do ensino" destaca a participação do professorado primário na semana de estudos pedagógicos "[...] Nada mais oportuno do que esta iniciativa, que vem justamente num momento em que todos sentimos a flagrante ineficiência do ensino que se ministra as nossas crianças" (Diário Da Borborema, 1958, p. 2, grifo nosso). A notícia segue apontando os traços dessa ineficiência e conduz que a instrução do ensino primário é suporte básico para eficiência do ensino secundário.

Está faltando organização, administração escolar, inspeção do ensino, melhor condição de remuneração para o professor, melhor preparação do mestre para as suas tarefas.

$\mathrm{Na}$ análise de profunda inadequação de nosso ensino primário, não poderemos deixar de encarar como problemas básicos a má organização dos estudos normais e a deficiência de salários dos professores primários. Ainda seria o caso de considerar-se também a influência negativa das nomeações de professoras por motivos partidários. (Diário Da Borborema, $1958, n^{\circ} 84$, p. 2).

Ratifica-se que o jornal evidencia grandes problemas na organização e instrução do ensino primário. São destacados problemas como a inadequação do ensino a má organização na formação organização dos estudos normais ${ }^{\text {viii a }}$ precariedade do salário e as nomeações das professoras, demonstrando, assim, falhas desde a incompatibilidade na formação, desde o provimento das regentes de ensino. Ademais, conforme Agra do Ó (2006, p. 14) "Percebe-se que a educação, naqueles anos, estava sendo constituída como um espaço privilegiado para a consecução de desejos". A educação não possuía em seu sentido primeiro a possibilidade de gerar cidadãos conscientes, letrados e passíveis de posicionamento, uma vez que o acesso à escola era restrito a uma minoria da sociedade que detinha sua função e consecução diante das atividades sociais. De uma forma mais aberta, o Diário da Borborema evidencia o problema educacional como algo bastante catastrófico em Campina Grande, pois, praticamente não se 
observa qualidade alguma na educação, perpassam por grupos escolares sem aparelhamento, salários baixos para professoras, além das nomeações que facilitam a presença do autoritarismo e dos favores na atuação em sala de aula, bem como algo até então não presente como o questionamento a organização dos estudos normais.

Assim, por conceber que a criação da Escola Normal estadual de campina Grande estava em vistas de planos, supomos que o jornal se refere ao Ensino Normal já existente na cidade. Salientamos que seriam essas escolas já existentes que não forneciam a educação desejada para o crescimento da cidade? Seria então necessário reestruturar e criar mais uma instituição? Cabe mencionar que a criação dessa nova instituição está atrelada a figura do estado, diferente das escolas já existentes, uma vez que são pertencentes à rede particular de ensino.

Após essas notícias que demonstravam o descontentamento do ensino primário e a cobrança para com o Estado em favor da melhoria da educação, o jornal anuncia no dia 18 de janeiro de 1958, pela primeira vez, o Instituto de Educação:

\section{INSTITUTO DE EDUCAÇÃO PARA CAMPINA GRANDE}

Também dois novos Grupos Escolares - Promete a administração do Governador Pedro Gondim voltar as suas vistas para o interior do Estado.

A reportagem deste jornal acaba de ser informada que um dos primeiros frutos da escola do Deputado Antônio Cabral para a Secretaria de Cultura e do escritor Lopes de Andrade para o deputado de Educação do estado será a breve construção em nossa cidade de um moderno edifício que servirá de sede ao futuro Instituto de Educação de Campina Grande, bem assim de mais dois Grupos Escolares, em cooperação com Instituto Nacional de Estudos e Pesquisas Educacionais.

\section{ENTENDIMENTOS}

O Deputado Severino Cabral, presidente do Diretório Municipal do PSD de Campina Grande, em entendimento com o Governador Pedro Moreno Gondim, manifestou o desejo de ver esta cidade equiparada à Capital do Estado em edifícios escolares, salientando o esquecimento a que as sucessivas administrações estaduais têm relegado Campina Grande.

O Chefe do executivo escolheu favoravelmente a reivindicação do deputado campinense, autorizando o estudo e o encaminhamento das providências necessárias para a concretização daquele empreendimento no prolongamento da Avenida Marechal Floriano.

O edifício do futuro Instituto de Educação será localizado no prolongamento da Avenida Marechal Floriano Peixoto em seguida á catedral em direção ao bairro do Santo Antônio.

Os novos grupos Escolares ainda não tem localização escolhida. No presente ano letivo funcionará o Grupo escolar Solon de Lucena, construído em 1937 e ainda fechado, por falta de autorização para abertura de matrículas. (Diário Da Borborema, 1958, n 87, p. 8, grifo nosso).

Os meios pelo quais circulavam a opinião campinense desejavam o pronunciamento do Estado na solução do problema educacional. Sendo assim, entre o desejo de equiparação em prédios escolares campinenses em relação à capital do Estado se mostrava muito mais uma manobra política do que uma intervenção propicia a formação de professoras. Cabe destacar também o apelo ao edifício escolar, que é caracterizado como moderno e já aponta localização para sua construção. Nesse sentido, acentuamos o descompasso em proposições educacionais em relação a Campina Grande e João Pessoa, revelando citar que o jornal Diário da Borborema de 26 de setembro de 1959 evidencia o esquecimento do 
governo estadual para a cidade de maior crescimento no Estado, relegando uma equiparação não no que condiz aos edifícios somente, mas a condição de relevância social.

Em relação ao Semanário Municipal Oficial, este evidencia, em suas matérias a partir de outubro de 1958, a atuação do governo municipal frente à criação da Escola Normal Estadual para Campina Grande. Na matéria, consta a cobrança de uma maior atenção do governo estadual para com a cidade que visto seu desenvolvimento industrial possui uma arrecadação de tributos maior que a própria capital. No entanto, quando condiz de verbas para manutenção e aplicação de serviços básicos como saúde e educação a cidade apresenta inúmeras debilidades.

Ademais, no dia 28 de janeiro 1958 é ratificada no jornal Diário da Borborema a notícia acerca da criação dessa instituição

\section{INSTITUTO DE EDUCAÇÃO}

A criação do Instituto de Educação de Campina Grande, mantido pelo Estado em benefício da formação da juventude feminina de nossa cidade com vistas a futuras lides das mais capazes no magistério primário, bastaria para merecer a presença de dois representantes desta terra na atual equipe que dirige os destinos da Paraíba.

[...] essa será uma iniciativa para a qual se podem prever os mais lisonjeiros frutos. Um Instituto de Educação exige para ser digno desse nome um professorado capaz, possuidor dos requisitos que se torna indispensáveis para formadores de mestres da infância.

[...]

A decadência do ensino primário, que se revela a cada passo e aumenta de ano para ano, começa pelas Escolas destinos de Campina Grande e da região que tem por centro de atração a nossa cidade, pelas oportunidades que ela oferece e poderá melhor oferecer, em matéria de ensino secundário, normal e superior.

A criação do Instituto em Campina Grande será decorrência da exigência de um bom Colégio, se afana uma equipe de professores amantes de sua profissão e desejosos de melhorar os índices de preparação secundária de nossa mocidade, condição essencial do desenvolvimento da cidade.

A população recebeu com alegria a notícia da fundação do Instituto. Pequenos aprontos que poderiam retardar essa iniciativa, seriam talvez resolvidos com o aproveitamento do prédio do próprio Colégio Estadual, em caráter provisório, para o funcionamento das classes do Instituto. Vamos esperar pela ação dos representantes de Campina Grande da atual equipe administrativa do Estado. (Diário Da Borborema, 1958, n89, p. 2).

O intuito educativo dessa formação era atender às moças campinenses, ou seja, a Escola Normal Estadual de Campina Grande se compunha efetivamente enquanto um espaço educacional feminino.

No que concerne à melhoria do ensino, é tratado como necessária a dedicação e amor com devoção a essa profissão. Assim, ainda destacamos a necessidade dos professores formadores possuírem também o anseio de preparar o ensino secundário como condição determinadora para o desenvolvimento não apenas dos jovens, mas em especial da cidade. Por fim, observamos também o primeiro sinal de manifestação da população que, conforme notícia do dia 18 de janeiro de 1958 do jornal Diário da Borborema recebeu de forma entusiasmada a criação dessa instituição. No entanto, não há destaque de que parte da população era essa, uma vez que, conforme notícia seguinte, do dia 21 de janeiro de 1958 o jornal ratifica a debilidade do ensino primário "[...] A decadência do ensino primario, que se revela a cada passo e aumenta de ano para ano". (Diário Da Borborema, 
1958, p. 2). Apresentando a criação da Escola Normal enquanto solução para "[...] melhorar os índices de preparação secundária de nossa mocidade, condição essencial do desenvolvimento da cidade" (Diário Da Borborema, 1958, p. 2).

Embora a notícia acerca da criação da Escola Normal seja registrada com entusiasmo no início do ano de 1958, o Semanário Municipal Oficial, de Campina Grande, apresenta a notícia oficial apenas no mês de novembro também do ano de 1958. A matéria consta da resposta a outro oficio do governador, este endereçado ao prefeito, onde o dirigente municipal comunica o que a prefeitura doará o terreno necessário para construção da Escola Normal, destacando que a prefeitura colaborará com esse empreendimento.

\section{INSTITUTO DE EDUCAÇÃO PARA CAMPINA GRANDE}

Comunica o Prefeito Elpídio de Almeida que a Prefeitura doará o terreno necessário - Resposta à solicitação feita pelo Governador Pedro Gondim

No fim do mês de outubro passado o Governador Pedro Gondim, em ofício dirigido ao Prefeito Elpídio de Almeida, solicitou a cooperação da Prefeitura no sentido de ser doado ao Estado terreno na área urbana desta cidade, destinado à construção do edifício do Instituto de Educação de Campina Grande, obra a ser realizada pelo Governo da Paraíba em colaboração com o Instituto Nacional de Estudos Pedagógicos, do Ministério da Educação e Cultura.

Respondendo a solicitação do Governador, o Edil Campinense acaba de informar que a Prefeitura colaborar também no importante empreendimento, oferecendo o terreno necessário [...]. (Prefeitura Municipal De Campina Grande, 1958, p. 1).

Além das inquietações já citadas em nosso estudo, cabe destacar que, por vezes, as notícias acerca da construção desse edifício escolar suscitam como Instituto de Educação ora como Escola Normal. Apenas na obra Da cidade de pedra à cidade de papel: Projetos de educação, projetos de cidades Campina Grande (1959), de Alarcon Agra do Ó (2006), observamos a intenção por parte da sociedade em possuir na cidade de Campina Grande um Instituto de Educação e uma Escola Normal. Em nossos dados, encontramos nas primeiras matérias do mês de janeiro de 1958 do Diário da Borborema a presença dos termos: Instituto de Educação e Escola Normal, a única distinção que aparece entre esses dois termos é que a escola seria apropriadamente para o público feminino, "O educandário em aprêço, segundo dispoe o ante-projeto constará de um Ginasio feminino, uma Escola de Aplicação e uma Escola de Professores, ficar pronta no próximo ano, quando entrará em funcionamento" (Diário Da Borborema, 1958, p. 8). no demais ainda não temos fontes suficientes que aclarem a afirmação da proposta de criação de duas instituições para Campina Grande.

$\mathrm{Na}$ notícia de 29 de novembro de 1958 no semanário Oficial, consta a possível parceria municipal e estadual e reafirma a colaboração do INEP. Ressaltamos alguns pontos da notícia, tais como: a doação do terreno em local urbano, certamente local de visibilidade e próximo da população, ademais o termo de empreendimento o que nos possibilita deduzir que a criação dessa instituição suscitaria visibilidade para ambos os governos.

Mencionamos também que no início desse texto, destacávamos a posição dos alunos em relação a estrutura da instituição, que não aparentava o que foi prometido. No entanto, a mesma notícia demonstra um possível desacordo político que estava por impedir a efetiva criação da escola. Com efeito, antes mesmo de se 
cogitar o funcionamento da Escola Normal no Colégio Estadual já era previsto um prédio próprio com solicitação de local adequado, no entanto algo ocorreu, e que ainda não nos foi esclarecido, impediu essa realização.

\section{Considerações Finais}

Apesar dos periódicos apontarem de maneira cordial as possíveis divergências entre o governo estadual e municipal, a escola foi criada "por iniciativa do Governo do estado na gestão do Dr. José Fernandes de Lima, pela lei Estadual $n^{\circ}$ 2.229, publicada no Diário Oficial, edição de 08 de abril de 1960 com a denominação de 'Escola Normal Estadual'” (Escola Normal Estadual Padre Emídio Viana Correia, 2008, p.1). E, embora funcionasse de maneira precária em "instalações por empréstimo, se resumiam a duas salas, sendo uma para sala de aula, com apenas 25 alunos e outra para a direção, secretaria e arquivo". (Escola Normal Estadual Padre Emídio Viana Correia, 2008, p. 1). A instituição permaneceu em funcionamento em situação de comodatos até a ocupação do prédio com instalações próprias e apenas "Em 10 de maio de 1970, a Escola Normal passou a funcionar em prédio próprio construído para esse fim". (Escola Normal Estadual Padre Emídio Viana Correia, 2008, p. 1).

Acerca da relevância do estudo, apontamos as análises das fontes coletadas como instrumento de grande importância e aporte ao passado já vivido, porém pouco conhecido. Por fim, cabe indagar que frente à realidade educacional já criada e mantida no município pela rede particular e diante do quadro de professoras existentes, o que motivou a criação da Escola Normal Estadual? Teria sido o desejo da população ou o anseio de uma nova educação modernizante? Essas são algumas das questões ainda cabíveis de discussão.

Compreender como se determinou a criação de uma instituição escolar a nosso ver entrelaça as relações sociais e políticas que permeiam essa escola. As tramas políticas engendram um roteiro instigante e a imprensa revela destoantes enunciados até a concretização da promessa educativa.

\section{Referências}

Agra Do Ó, A. (2006) Da cidade de pedra à cidade de papel: Projetos de educação, projetos de cidades Campina Grande (1959). Campina Grande: EDUFCG. 151p. (Coleção Outras Histórias, n.5).

Andrade, V. G. de. CURY, C. E. (2013). "Construir a cidade e erguer a escola": O Caso do Instituto Pedagógico em Campina Grande (1919-1942). Revista Lugares de Educação. v.3, n.7. Disponível em:

http://periodicos.ufpb.br/ojs/index.php/rle/article/view/17306/pdf. Acesso em: 02 de setembro de 2014.

Araújo, R. M. de. (2009). O governo de Pedro Gondim e o Teatro do poder na Paraíba: Imprensa, imaginário e representações (1958-65). 2009. 139f. Trabalho de Conclusão de Curso (Dissertação) - Programa de Pós Graduação em História Universidade Federal da Paraíba (UFPB), João Pessoa.

Costa, L. B. da. (2013). Estruturação da cidade de Campina Grande: As estratégias e intencionalidades do mercado imobiliário. 194f. Trabalho de Conclusão de Curso 
(Dissertação) - Programa de Pós Graduação em Geografia (PPGG) - Universidade Federal da Paraíba (UFPB), João Pessoa.

Chamon, M. (2005). As mulheres entre as esferas públicas e privada. In.: Trajetória da feminização do magistério: ambiguidades e conflitos. Belo Horizonte: Autêntica/ FHC-FUMEC.

DIÁRIO DA BORBOREMA. Campina Grande - PB. (1958/1959) ESCOLA NORMAL ESTADUAL PADRE EMÍDIO VIANA CORREIA. (2008). Projeto Pedagógico.

ESTADO DA PARAÍBA. (1960). Atos do Poder Executivo. Diário Oficial, Ano III, № 226, 14 de abril de 1960.

Fernandes, S. T. (2011). Uma outra representação da modernização em Campina Grande: a cidade nas páginas do Diário da Borborema (1960/1980). 2011. 145f. Trabalho de Conclusão de Curso (Dissertação) - Programa de Pós Graduação em História - Universidade Federal de Campina Grande (UFCG), Campina Grande. GAZETA CAMPINENSE. Campina Grande/PB, 1959, 1960,1961.

JORNAL A UNIÃO. (1959). Vinte milhões de cruzeiros para construção da Escola Normal de Campina Grande. Campina Grande.

Kulesza, W. (2008). Formação Histórica da Escola Normal da Paraíba. In.: Araujo, J. C. S.; Freitas, A. G. B. de; Lopes, A. de P. C. (org.). As escolas normais no Brasil: do império à republica. Campinas: Alínea. p. 263-278.

Lima, L. C. de. (2013) Práticas e saberes disciplinares em Campina Grande Paraíba (1900-1930). XXVII Simpósio Nacional de História. Natal, RN. Disponível em: http://www.snh2013.anpuh.org/resources/anais/27/1364675786. Acesso em: 02 de setembro de 2014.

Nosella, P. BUFFA, E. (2013). Instituições escolares: por que e como pesquisar. Campinas, SP: editora Alínea. $2^{\text {a }}$ edição.

PARAÍBA. (1960). Mensagem à Assembleia Legislativa. Departamento de publicidade/Estado da Paraíba; junho de 1960.

PARAÍBA. (1959). Decreto-Lei que cria á Escola Normal. Memorial Assembleia parlamentar/ Estado da Paraíba; outubro de 1959.

PREFEITURA MUNICIPAL DE CAMPINA GRANDE. (1956). Semanário Oficial. Campina Grande, 1956.

. (1957). Semanário Oficial. Campina Grande.

(1958). Semanário Oficial. Campina Grande.

Rodrigues, M. M. Silva, V. de M. (2012). Colégio São José: considerações históricas da educação primária em Campina Grande Século XIX. In: IV Encontro Norte/Nordeste de História da Educação História da Educação: imprensa, impressos e práticas educativas, 2012, Aracaju - SE. IV Encontro Norte/Nordeste de História da Educação História da Educação: imprensa, impressos e práticas educativas. Aracaju - SE. v. 1. p. 1- 14.

Sanfelice, J. L. História das Instituições Escolares. (2007). In: Nascimento, M. I. M. et.al. (org.). Instituições escolares no Brasil: conceito e reconstrução histórica.

Campinas, SP: Autores Associados.

Sanfelice, J. L. Jacomeli, M. R. M. Penteado, A. E. de A. (orgs.). (2016). História de instituições escolares: teoria e prática. Bragança Paulista-SP: Margem da Palavra. $304 \mathrm{p}$.

Saviani. D. (2007). História das ideias pedagógicas no Brasil. Campinas-SP: Autores Associados. 
Soares, M. V. R. (2016). Curso Normal Regional de Mamanguape/PB (1949 - 1957): educação redentora para ascensão e controle social. 195f. Trabalho de Conclusão de Curso (Tese) - Programa de Pós Graduação em Educação - Universidade Federal do Rio Grande do Norte (UFRN), Natal.

Tanuri, L. M. (2000). História da formação de professores. Revista Brasileira de Educação, n.. 14, mai/jun/jul/ago de 2000 (Número Especial - 500 anos de educação escolar), p. 61-88. Disponível em: <http://www.scielo.br/pdf/rbedu/n14/n14a05> Acesso em: 12/08/2016. Vicentini, P. P. Lugli, R. G. (2009). História da profissão docente no Brasil: representações em disputa. São Paulo: Cortez. (Biblioteca básica da história da educação brasileira; v. 4).

Wachowicz, L. A. (2001). A dialética na pesquisa em educação. Diálogo

Educacional. v. 2 - n.3 - p. 171-181 - jan./jun.

\section{Notas}

i Algumas informações relativas à história da Escola Normal Estadual Padre Emídio Viana Correia, foram extraídas do projeto de pesquisa mais amplo intitulado "Escola Normal Estadual Padre Emídio Viana Correia-Campina Grande-PB: criação e consolidação (19601970)", em andamento na UFCG.

ii O acervo da biblioteca constituía o acervo pessoal do Professor Átila Almeida. Desde o ano de 2004, a Universidade Estadual da Paraíba é a responsável pelo acervo e gerencia o acesso ao meio acadêmico.

iii Fonte de dados para essa pesquisa. É um importante meio de informações da cidade de Campina Grande, possuía grande relevância social e destacava-se por publicar inúmeras notícias acerca do desenvolvimento campinense (FERNANDES, 2011).

iv Tratamos o jornal enquanto fonte primária por considerarmos que devido ao fato de não encontrarmos dados referentes a estudos que posicionem a relevância deste documento vPor essa particularidade, nos atemos a uma leitura mais cautelosa das notícias narradas, uma vez que se trata do principal fomentador de informações do Estado paraibano.

viCom destaques para o Jornal A União, como já mencionado órgão oficial do Estado.

vii $A$ cidade não possuía um crescimento continuo, à medida que cresce o seu valor econômico as estruturas sociais não acompanhavam o mesmo ritmo, moradias eram insuficientes, saúde passa a ser precária, há o problema acerca da falta de água e a educação era concebida ainda enquanto uma concessão, de modo que as poucas instituições existentes eram de caráter privado.

viiiA cidade contava, até o início da década de 1960, apenas com instituições equiparadas à Escola Normal de João Pessoa, o Colégio Imaculada Conceição e o Instituto Pedagógico, atual Colégio Alfredo Dantas (CAD), estabelecimento particular, cuja equiparação ocorrera ainda na década de 1929. 